ACP documented. Most patients had hospital admissions during this time (23/27), more than one third of patients were referred to the Palliative Care Team. During the last 7 days of life 19/27 patients were recognised as dying, and had their wishes documented, all patients had DNA-CPR in place and 18/27 were referred to the Palliative Care Team.

Conclusions From this audit there were significant opportunities for healthcare workers to identify patients in the last 12 months of life, if this can be recognised sooner advanced care planning could be offered earlier to patients. These results suggest a need to make use of tools such as the Gold Standard Framework to better recognise patients who may be approaching end of life in order to help plan their preferred care.

\section{P-105 END OF LIFE CARE AT THE WEEKEND IN A UK DISTRICT GENERAL HOSPITAL}

Katharine Perry, Holly Randall, Katherine Webb. Royal Surrey County Hospital, Guildford, UK

\subsection{6/bmispcare-2017-00133.104}

Background In 2014 an independent review (Neuberger report) recommended discontinuation of the Liverpool Care Pathway. A subsequent report advised replacing the LCP with individualised end of life care plans, the contents of which were to be determined at local level.

The Supportive and Palliative Care Team (SPCT) at a UK District General Hospital and Cancer Centre developed a Personalised End of Life Care Plan (PELiCan) encompassing the five key priorities of care (One chance to get it right). Each patient on the PELiCan is assessed daily by a member of the SPCT. This study aimed to assess the use of the PELiCan and the utilisation of a seven day SPCT service.

Methods A database was created and every patient commenced on a PELiCan was entered. This database was retrospectively analysed over a 2 year period $\left(1^{\text {st }}\right.$ Sept 2014 and $31^{\text {st }}$ August 2016). Descriptive statistics were used to assess demographic details and diagnosis. The day each PELiCan started was noted as well as the date of death or discontinuation.

Results Nine-hundred and ten patients had an end of life care plan. The most common diagnosis was cancer (27\%), followed by diseases of respiratory system $(25 \%)$ and disease of circulatory system $(16 \%)$.

Twenty four percent $(n=222)$ of patients with a PELiCan died on a Saturday or Sunday. Five hundred and thirty-two patients $(58 \%)$ with a PELiCan were reviewed daily over the weekend. One-hundred and forty patients (15\%) were started with a PELiCan during the weekend (Saturday $n=56$, Sunday $\mathrm{n}=84$ ). Of these patients $34 \%$ had died before $9 \mathrm{am}$ on Monday morning.

Conclusions A significant proportion of end of life assessment and support occurs at a weekend. There is a requirement for seven-day palliative care services to implement effective specialist end of life symptom assessment.

\section{P-106 CHECKPOINT CHARLIE: AUDIT OF REGULAR SYRINGE DRIVER CHECKS ACROSS HEALTHCARE SETTINGS}

${ }^{1,2}$ Joseph Rassam, 1,2 Akash Chowdhury, 1,3,4 Karen Groves. 'West Lancs, Southport and Formby Palliative Care Services, Southport, UK; ${ }^{2}$ Liverpool University; Southport and Ormskirk Hospitals NHS Trust; ${ }^{4}$ Queenscourt Hospice, Southport

10.1136/bmjspcare-2017-00133.105

Background Syringe drivers are integral part to palliative care practice. The most widely used model, McKinley T34, is used to administer controlled drugs including opioids. As a result the documentation and monitoring of the use of syringe drivers is vital for ensuring safe treatment and in prevention or detection of potential adverse events.

Aim The aim of this audit was to review how effectively syringe driver checks and the subsequent documentation of such checks were carried out for patients in hospital, community and hospice settings.

Method Standards were set using current guidance and safety information. Patients were systematically identified through the help of the transform team (a palliative care liaison team), contacting the medical equipment library responsible for issuing the syringe drivers and by systematically going round the wards in the hospital setting. The checklists were analysed using a predetermined spreadsheet. A second improved checklist was introduced and the process repeated.

Results Data from the first cycle indicated the frequency of syringe driver checks was half that of the required 6 per day. A number of important safety parameters were under recorded and reasons identified included misleading questions and poor formatting of the syringe driver checklist (eg, questions on the reverse side of the page). After implementing the new sheet some modest improvements were made, most notably the documentation of syringe volume and syringe brand improved. Hospice and community data checklists were completed more accurately in accordance with clinical guidelines, compared to the hospital setting.

Conclusion The implementation of a checklist with clearer questions and an improved format resulted in some improvement. However the discrepancy between the hospital and community/hospice setting, where staff are more experienced with the use of syringe drivers, indicates the potential need for more training amongst hospital staff.

\section{P-107 IDENTIFICATION AND EVALUATION OF OBSERVATIONAL MEASURES FOR MONITORING SEDATION IN ADULT PALLIATIVE CARE PATIENTS: FINDINGS FROM A SYSTEMATIC REVIEW FOR I-CAN-CARE}

${ }^{1}$ Anna-Maria Krooupa, ${ }^{1}$ Bella Vivat, ${ }^{1}$ Bridget Candy, ${ }^{2}$ Stephen McKeever, ${ }^{1}$ Elena Marcus, ${ }^{1}$ Nuriye Kupeli, ${ }^{1}$ Paddy Stone. 'University College London, London, UK; ${ }^{2}$ Department of Children's Nursing, London South Bank University, London, UK

10.1136/bmjspcare-2017-00133.106 